\title{
LA JUSTICIA CONMUTATIVA EN CALDERÓN Y SU SOLUCIÓN AL ADULTERIO: UXORICIDIO O INDULTO
}

\author{
Catarina Valdés Pozueco \\ UNED (Universidad Nacional de Educación a Distancia) \\ Facultad de Filología \\ Apdo. de correos 60.145 \\ 28080 Madrid. España \\ kavaldespo@gmail.com
}

Calderón de la Barca trató en varias de sus obras el delito del uxoricidio por adulterio. Este delito de sangre se encuadraba en la justicia conmutativa y tenía carácter privado; era, ante todo, un problema doméstico. Las leyes de la época consentían la venganza privada, protegiendo la honra mancillada del marido. Detrás de la acción cruenta había todo un pensamiento jurídico y ético que condicionaba el comportamiento de los protagonistas. Pero para fijar el contexto y profundizar en la problemática, era necesario conocer la normativa de ese periodo y, así, discernir dónde terminaba la realidad y dónde comenzaba la ficción. Por otro lado, se ha hablado hasta la saciedad del honor marital y sus consecuencias; algunos investigadores se centraron en las Partidas, otros en los Repertorios o compilaciones y algunos en tratados moralistas; era evidente que el caos legal reinante en el siglo Xvir llegaba incólume a nuestra época. Sin embargo, la ley era clara al respecto y establecía un

RECEPCIÓN: 17.11.15 / ACEPTACIÓN DEFINITIVA: 26.11.15

[Anuario Calderoniano (ISSN: 1888-8046), 9, 2016, pp. 217-236] 
orden de precedencias. Se hacía necesario distinguir las leyes preferentes que imperaban en la sociedad calderoniana frente a la doctrina jurídica, los moralistas y los compiladores. Solo así lograríamos acercarnos al máximo a la obra de nuestro dramaturgo.

Y frente a la solución de la ley, aparece Calderón poniendo el dedo en la llaga, tratando un mismo delito y ofreciendo diferentes soluciones jurídicas: desde la justicia conmutativa y retributiva, en la que prima la venganza o la existencia como pena, a la justicia divina del perdón y la misericordia. Los maridos calderonianos se convertían al mismo tiempo en jueces, fiscales y abogados defensores, y lo más importante, respondían de forma diferente si estábamos ante un drama, una comedia o un auto. Estos héroes y antihéroes sufrían la injusticia de la ley y de un código ético que les condenaba sin ser responsables del delito, obligándoles a la venganza si querían mantener su honor intacto. Mientras, las damas intentaban sobrevivir entre el miedo y el deseo de salvar sus vidas. $\mathrm{Y}$ todas ellas eran inocentes.

La justicia conmutativa estaba vinculada al concepto de justicia retributiva proporcional. Calderón nos propone algo de plena actualidad: la existencia como castigo. Alejándonos de las teorías que condenaron al propio dramaturgo, proponemos una visión que enlaza con nuestra contemporaneidad más cercana. Don Pedro nos ha hablado, y mucho, sobre la justicia. No juzgaba ni condenaba de forma evidente, pero observando las obras que tratan el uxoricidio y las soluciones que nos ofrece, podemos extraer todo un pensamiento jurídico y ético que ha despistado a la crítica durante siglos, que ha dado mucho que reflexionar y que sigue removiéndonos aún hoy.

\section{RELACIÓN ENTRE UXORICIDIO Y JUSTICIA CONMUTATIVA}

La justicia conmutativa trata la relación entre particulares. Aristóteles la definía como la justicia que se aplica voluntariamente ${ }^{1}$, y santo Tomás matizaba este concepto definiéndola como aquélla que atiende "a los intercambios que acontecen entre dos personas ${ }^{2}$. Rige el principio de proporcionalidad. El uxoricidio es «la muerte causada a la mujer por

\footnotetext{
${ }^{1}$ Aristóteles, Ética a Nicómaco, lib.V, p. 4.

2 Tomás de Aquino, Suma teológica, II-II, c. 61, art. 3.
} 
su marido» ${ }^{3}$. Esta nomenclatura no aparecía en las leyes del Antiguo Régimen, aunque el delito existía y se consideraba un tipo de asesinato. Las fuentes jurídicas en las que nos centramos para tratar estos temas se basan, principalmente, en la Nueva Recopilación y en las Partidas como Derecho supletorio. Es importante resaltar este hecho, porque los estudios calderonianos que hasta el momento se han acercado a la materia jurídica del uxoricidio por adulterio recogen tratados, enumeran las Partidas como fuente primera, incluso el Fuero juzgo, pero no mantienen el orden de precedencias estipulado en la época ${ }^{4}$. A pesar del aparente caos legal del xviI, la Nueva Recopilación de las Leyes de España había sido clara al establecer un orden de precedencias: en primer lugar, se atendería a la Nueva Recopilación y, seguidamente, a las Partidas como Derecho supletorio ${ }^{5}$.Y éste es el criterio que vamos a seguir 6 . Además, es importante la opinión del padre Antonino Diana, porque su Suma estuvo en la biblioteca de Calderón hasta su muerte ${ }^{7}$. Igual relevancia juega la Filosofia del Derecho, concretamente el probabilismo, tan de moda entre los jesuitas del xvir; las reflexiones y debates de los teólogos-juristas son un buen índice para evaluar el nivel de preocupación existente en la sociedad respecto al adulterio, el honor y la posterior venganza.

El problema se plantea cuando hay una ley, como es la del adulterio, y hay unos protagonistas que la consideran injusta. Así, don Lope de Almeida nos dice: «¿En qué tribunal se ha visto / condenar al inocente? / ¿Sentencias hay sin delito? / ¿Informaciones sin cargo? / ¿Y sin

${ }^{3}$ DRAE, 2001. Es un término compuesto que procede del latín, de la composición uxor-oris 'esposa' y caedere 'matar'.

${ }^{4}$ Para una idea clara del panorama imperante en la Edad Moderna, ver el estudio realizado por Antonio Pérez Martín y Johannes-Michael Scholz, Legislación y jurisprudencia en la España del Antiguo Régimen (1978).

5 «Tenemos que partir de la base de la enorme complejidad del mundo del Derecho en el Antiguo Régimen [...]. En los siglos XVI y Xvir los pilares básicos del Derecho castellano fueron la Nueva Recopilación de 1567 y el código de las Partidas como Derecho supletorio»; en García Hernán, 1992, p. 17.

${ }^{6}$ Como la Novísima recopilación, publicada en 1805, recoge también las leyes del xvII, la Recopilación de 1567 y las leyes anteriores, será la Novísima el texto básico legal que utilizaré en este artículo.

7 «Ítem es mi voluntad que los libros del padre Diana se den y entreguen a Gerónimo de Peñarroja»; en Testamento e inventario de bienes de P. Calderón en el Archivo Histórico de Protocolos de Madrid, 2000, p. 48. 
culpas hay castigo?»; o don Curcio se pregunta: «¿Qué ley culpa a un inocente? / ¿Qué opinión a un libre agravia?»" La Novísima recopilación cita en la Ley 1, título 7, libro 4 del Fuero real y en la Ley 1, título 21 del Ordenamiento de Alcalá el caso de adulterio cometido por la esposa y el derecho del marido a la venganza: «Si mujer casada hiciere adulterio, ella y el adulterador ambos sean en poder del marido, y haga de ellos lo que quisiere, y de cuanto han, así que no pueda matar al uno y dejar al otro $[\ldots] »^{10}$.

Calderón, a través de sus maridos ofendidos, nos plantea si una ley considerada injusta puede obligar. Domingo de Soto, en este sentido, lo tenía claro: la ley injusta no tiene autoridad para obligar en conciencia. Ahora bien, ¿cómo sabemos cuándo una ley es injusta? Mediante dos formas: cuando es contraria al bien divino o al humano. Si es contraria al bien humano, puede obligar algunas veces, solo para evitar escándalo ${ }^{11}$. Siglos antes, santo Tomás, en la Suma, había hablado de las leyes injustas, las cuales «no obligan en el foro de la conciencia, a no ser que se trate de evitar el escándalo o el desorden, pues para esto el ciudadano está obligado a ceder de su derecho»" ${ }^{12}$. El conflicto estaba servido, porque la ley civil era opuesta a las leyes eclesiásticas, y además, la honra exigía un tipo de comportamiento del esposo que, a veces, colisionaba con sus propios sentimientos, enfrentándose cara a cara obligación social y deseo personal. Los protagonistas uxoricidas calderonianos padecen el rigor de una ética con fuerza de ley que no les deja escapatoria. Ignacio Arellano lo explica de la siguiente forma: «La presión de una ideología — dramáti$\mathrm{ca}$ - convertida en esquema rígido que obliga a los individuos y que se coloca por encima de ellos es la fuente de la destrucción trágica para los protagonistas. El ejecutor destruye y queda destruido $[\ldots]\rangle^{13}$.

Calderón supo sacar el máximo partido a la situación, de tal forma que concede al código ético del honor una obligatoriedad mayor que

${ }^{8}$ Calderón de la Barca, A secreto agravio, secreta venganza, p. 183.

${ }^{9}$ Calderón de la Barca, La devoción de la Cruz, 2000, p. 157.

${ }^{10}$ Los Códigos españoles, concordados y anotados, Novísima recopilación, tít. XXVIII, 1. 2, p. 94.

11 «Aquellas leyes que solo se oponen al bien humano, aunque en conciencia no obliguen de suyo, obligan algunas veces en razón del escándalo; mas las que se oponen impías contra el bien divino, nunca, antes hay que hacerles resistencia abiertamente...»; en Soto, 1922, p. 150.

12 Tomás de Aquino, Suma teológica, III, c. 96, art. 5, p. 751.

${ }^{13}$ Arellano, 2000, p. 8. 
si de la misma ley se tratase. Por otro lado, las leyes de la época, como hemos visto anteriormente, amparaban la venganza y permitían el uxoricidio. Por supuesto, se consideraba un asunto doméstico, de carácter privado, en el que se aplicaba la justicia conmutativa. Si la deshonra implicaba la muerte social del marido burlado, la proporcionalidad que regía la justicia conmutativa exigía, según la ley, la muerte de los adúlteros. Solo así se podría recuperar la estima social. Los personajes se encontraban en una encrucijada en la que la primera víctima, el esposo injuriado, sentía la injusticia en carne propia al tener que vengar un delito que él no ha cometido. «Donde no hay culpa, ¿hay delito?», se plantea don Juan Roca, mostrando el conflicto entre fuero interno y externo: «iY que me condene yo / por el ajeno albedrío [...] / Siendo otro el delincuente, / de su malicia afrentosa / ¡que a mí el castigo me den!»».

La queja de don Juan, independientemente de su belleza lírica, plantea como trasfondo varias cuestiones jurídicas. Por un lado, hay una ley escrita que permite el uxoricidio y la venganza privada. Esta ley no obliga a matar, pero concede el derecho a ella. Por otro lado, está la ley divina, opuesta al asesinato; $y$, sobre todo, está la conciencia del marido burlado, que se ve obligado a asesinar a quien ama para solventar una obligación social con tal fuerza que coacciona el comportamiento del individuo como si fuese la misma ley escrita. Si la ley no obligaba a la venganza, solo la permitía, la condición del noble convertida en costumbre, apelando al honor, era el requisito definitivo para el homicidio. Antonino Diana lo dejó claramente expresado cuando afirmaba en su Suma: «la costumbre hace ley» y "para que la ley obligue, conviene que no sea arrogada por el uso contrario» ${ }^{15}$. Si la ley no obligaba al uxoricidio, solo lo permitía, la costumbre, igual que en el duelo ${ }^{16}$, matizaba la ley y condicionaba el comportamiento de los individuos. El fin último de la ley era evitar el escándalo y la deshonra del noble injuriado. Calderón juega con la obligatoriedad del fuero externo para condicionar el fuero interno del individuo. La pregunta que se hacen don Juan, don Lope o don Curcio sobre la posibilidad de ser culpables sin cometer un delito hiere el mismo sentido de la justicia, pues se presuponía que el

${ }^{14}$ Calderón de la Barca, El pintor de su deshonra, p. 584a.

${ }^{15}$ Diana, Suma: recopilado en romance, p. 501.

${ }^{16}$ El tema del duelo calderoniano y su relación con la justicia legal está tratado en mi tesis doctoral El mundo jurídico de Calderón y su sentido de la justicia humana (Valdés Pozueco, 2015). 
culpable era quien cometía el delito o tenía la voluntad de hacerlo. Lo terrible es que aquí el delito de adulterio lo efectúan otros, pero la punición social recae en un tercero.Y el marido burlado se ve en la tesitura de aplicar la ley y cometer uxoricidio, o seguir los dictados del Derecho canónico y perdonar a la adúltera. Calderón adopta en sus dramas la posición más terrible, el uxoricidio, y va más lejos aún, porque la gran víctima, la esposa, resulta que es inocente del delito que se le imputa y el marido se convierte en juez y verdugo, transformando su lamento contra la ley en otro acto más injusto aún, como es la muerte de un inocente.Y el homicidio de un inocente no era lícito. Santo Tomás lo recoge en el artículo 6, cuestión 60 de la Suma (IIII), y Bartolomé Carranza así lo ratifica: «[...] de ningún modo es lícito matar a un inocente» ${ }^{17}$. La crítica que Calderón hace a las leyes de la época y sus costumbres no puede ser más clara. Diferente intención hubiese mostrado el autor si hubiera puesto en escena a una dama lujuriosa e infiel, condenable ante la sociedad. Pero sigamos adelante.

A la hora de tratar el uxoricidio en Calderón hay que tener en cuenta que éste iba vinculado principalmente al tema del honor, el adulterio y los celos, y que éste estaba penalizado por ley ${ }^{18}$. Se establecía, además, una clara diferencia entre el adulterio femenino y el masculino. De hecho, el uxoricidio cometido por un atentado contra el honor del marido tenía carácter privado, porque atacaba directamente la fama del individuo. Tanto el adulterio como el uxoricidio estaban intrínsecamente unidos a las leyes de la época. Ambos formaban parte de la justicia conmutativa; eran infracciones de carácter privado y, por ello, constituían el escenario idóneo para la venganza personal ${ }^{19}$.

Calderón trata el problema en sus dramas de honor ( $E l$ médico de su honra, $A$ secreto agravio, secreta venganza, El pintor de su deshonra) y en otras obras de distinto matiz genérico, como La devoción de la Cruz, El mayor monstruo del mundo, Gustos y disgustos no son más que imaginación

17 Carranza, Tratado sobre la virtud de la justicia, p. 170.

${ }^{18}$ La despenalización del adulterio se aprobó en 1978.

19 «La jerarquía española no denunció en ningún momento el legalizado uxoricidio por adulterio pese a que el papa lo había condenado moralmente. La sociedad católica española consideró la cuestión de poca importancia, de orden interno de las familias, regidas por un celoso patriarca calderoniano, provisto de todos los derechos e impunidades e incluso la posible muerte de la adúltera. Así, el marido fingía o fomentaba muchas veces el adulterio de su esposa para divorciarse a la carta, quedando impune hasta ayer mismo en las sociedades latinas»; en Lorenzo Vián, 2000, p. 171. 
y El pintor de su deshonra (auto). Y es que el hombre en conflicto con una norma externa, como es la del honor, la lucha entre la razón y sus sentimientos crea el escenario perfecto para el drama. Calderón supo aprovechar esta oportunidad a través de un delito que iba más allá del mero crimen $^{20}$; removería la conciencia social e impugnaría de forma indirecta unas leyes que, aun partiendo del legislador máximo, el rey, concedían libertad al individuo para vengar de forma particular la infamia contra su persona.

\section{SOluCiones de CALderón AL UXORICIDIO POR ADULterio}

Tanto en las «tragedias» El pintor de su deshonra como en $A$ secreto agravio, secreta venganza, amante y esposa mueren a manos del marido supuestamente burlado. Ésta es la solución que nos ofrece el dramaturgo madrileño aplicando la ley y la justicia conmutativa. Rige, por tanto, el principio de retribución proporcional y la venganza privada. Si la Nueva Recopilación permitía el uxoricidio, ni a don Lope de Almeida ni a don Juan Roca les temblará la mano para ejercitar su derecho de esposo injuriado. Mientras, el espectador se compadece de la pobre Serafina, secuestrada por su amante y llevada y traída como un títere sin voluntad propia. Leonor, en cambio, se debate entre el honor y el amor, y cuando el miedo al adulterio parece ser vencido y se cita con don Luis de Benavides, su marido impide el encuentro con la muerte de ambos. También en El médico de su honra fallece la protagonista, Mencía, pero a diferencia de las anteriores, queda indultado el supuesto amante. Esta respuesta de perdonar al amante no es única en Calderón. El lector puede encontrarla en la comedia Gustos y disgustos no son más que imaginación, donde la esposa, Violante, a diferencia de la trilogía del honor y gracias a la actitud y al empeño por salvar su vida ${ }^{21}$, logra deshacer el enredo y vivir felizmente con el hombre que ama, su marido. ¿Qué ocurre cuando el amante es un superior jerárquico respecto al marido engañado? Las leyes de la época recogían el caso y Calderón parece seguir fielmente la ley.

\footnotetext{
${ }^{20}$ Lope de Vega, en El arte nuevo de hacer comedias, había establecido: «Los casos de honra son mejores / porque mueven con fuerza a toda gente» (vv. 327-328).

${ }^{21}$ La oposición de la dama calderoniana a la norma injusta hace que el dramaturgo la salve o la condene. Ver mi artículo «Dña. Angela y Dña. Mencía: dos respuestas ante la ley» (Valdés Pozueco, 2008).
} 


\section{a) El uxoricidio ante un superior jerárquico}

Nuestro dramaturgo va más allá de la Nueva Recopilación y plantea un conflicto de intereses legislado específicamente en las Partidas. Me refiero al caso mencionado, en el que el supuesto amante es el rey o un superior en el escalafón social al que el esposo le debe respeto y obediencia; la muerte del adúltero es imposible, porque se cometería otra infracción que sobrepasaría el carácter privado de la venganza; se atentaría contra la justicia legal y distributiva, constituiría un delito de traición y se rompería esa armonía social tan platónica y, al mismo tiempo, tan calderoniana. De hecho, críticos como Albert S. Gérard explican la absolución del rey hacia Gutierre en el hecho de que éste no hizo peligrar ni «la estabilidad social ni la paz estatal»" Tanto en El médico de su honra como en Gustos y disgustos no son más que imaginación, esta solución queda explícitamente detallada. Así, en la comedia, don Vicente, sospechando del adulterio de su esposa con el rey, exclama: «Violante y el rey me agravian; / y pues no puedo tomar / más que la media venganza, / muera Violante, el rey viva ${ }^{23}$. Ramón Menéndez Pidal comentaba que los agravios del rey no se vengan y que el honor solo cedía ante el soberano ${ }^{24}$.

Como vemos, Calderón no difiere de las propuestas de otros dramaturgos, como Lope (piénsese, por ejemplo, en La locura por la honra). Mal lo tenía don Vicente, pero también difícil don Gutierre, porque, aunque el infante no fuese su rey, sí tenía un estatus superior y las Partidas eran claras al respecto. El no poder vengarse del supuesto amante estaba concretamente recogido en la Partida viI, título 17, ley 13, cuando se explica:

El marido que hallare a algún hombre vil en su casa o en otro lugar yaciendo con su mujer, puédelo matar sin pena ninguna [...]. Pero si este hombre vil fuere tal a quien el marido de la mujer deba guardar y hacer reverencia, como si fuese su señor u hombre que lo hubiera hecho libre, o si fuese otro hombre honrado y de gran lugar, no le debe matar por ello,

${ }^{22}$ Gérard, 1965, p. 222, cit. Armendáriz en Calderón de la Barca, El médico de su honra, 2007, p. 87.

${ }^{23}$ Calderón de la Barca, Gustos y disgustos no son más que imaginación, p. 989a.

${ }^{24}$ Todos los móviles humanos debían subordinarse al honor, mientras que el honor solo cedía ante la persona del rey. En multitud de comedias trágicas se expone la doctrina de que los agravios que proceden del rey no se vengan, aunque atropellen la honra del vasallo (ver Menéndez Pidal, 1945, p. 143). 
mas débele hacer afrenta de cómo lo halló con su mujer y acusarle de ello ante el juez del lugar, y el juez, después que supiere la verdad, puédele dar pena de adulterio.

Ni don Gutierre en el caso del infante, ni don Vicente en el caso del rey tienen en mente vengarse de ellos. Lo que está claro es que parecen actuar según el probabilismo de Francisco Suárez, y ante una duda, matar a su mujer o a ambos, eligen la opinión menos mala para ellos ${ }^{25}$. Si las leyes eran indulgentes en los casos de venganza privada con las damas, no lo eran, como hemos visto, cuando el amante era jerárquicamente superior. La única opción que les quedaba era acudir al juez, y así en parte lo hace don Gutierre cuando le expone hipotéticamente su caso al rey don Pedro. La sentencia de éste es clara: sangrar a la esposa, pero de su hermano el infante no comenta ni una palabra ${ }^{26}$. El que no condene a don Gutierre por el uxoricidio nos deja la duda de si le está premiando por no atentar contra el infante o si le está castigando, condenándole en vida al casarle con una mujer que no ama. ¿Nos está proponiendo Calderón una nueva pena, la existencia como castigo?

\section{b) La existencia como castigo}

El dejar sin castigo al delincuente no es nuevo en nuestra historia cultural.Ya Platón recoge en Gorgias un diálogo en el que Sócrates defendía la impunidad del delincuente como el mayor castigo y desgracia $^{27}$. Así desconcertaba el filósofo ateniense a sus contemporáneos:

En el caso de que nuestro enemigo cometa injusticia con otro, hay que conseguir por todos los medios, con obras y palabras, que no pague su culpa

${ }^{25}$ Vacant, Mangenot y Amann, 1936, p. 474.

${ }^{26}$ Henry W. Sullivan ha visto en este final la lucha entre los probabilistas laxistas, encarnada en la figura de don Pedro, y la actitud rigorista, en don Gutierre, y cómo al final Calderón condena sendas actitudes. Sullivan, cit. Armendáriz en Calderón de la Barca, El médico de su honra, 2007, p. 199.

27 «Tú considerabas feliz a Arquelao, aunque había cometido los mayores delitos, porque no sufría ningún castigo. Por el contrario, creía yo que, si Arquelao o cualquier otro hombre comete injusticia y no sufre el castigo, le corresponde ser el más desgraciado de los hombres, y que siempre el que comete injusticia es más desgraciado que el que la sufre, y el que no recibe el castigo de su culpa, más que el que lo recibe»; en Platón, Diálogos, II, p. 75. 
ni vaya ante el juez; y si va, procurar que sea absuelto y no reciba castigo nuestro enemigo; $[. .$.$] si ha cometido un delito que merece la muerte,$ procurar que no muera a ser posible nunca, sino que viva inmortal en la perversidad, y de no ser así, que su vida se prolongue en este estado el mayor tiempo posible ${ }^{28}$.

Siglos más tarde, la genialidad de Calderón elabora una obra en la que el protagonista mata a su esposa desangrándola y el rey, juez supremo, imparte una justicia diferente: le deja libre, casado con su antigua dama y conservando su estatus nobiliario. No le aplica una justicia retributiva proporcional en la que la muerte de la víctima se saldaría con la muerte de su asesino.Y este final llama la atención de la crítica, como en su día debió llamar la atención del espectador ${ }^{29}$. Calderón se opone a la justicia retributiva del castigo proporcional y propone una solución de plena actualidad: la existencia como castigo ${ }^{30}$. ¿No es éste uno de los varios mensajes que podemos encontrar en películas tan de actualidad como Match Point $?^{31}$ ¿Podrá Chris Wilton vivir tranquilamente con sus remordimientos o volverá a asesinar si ve de nuevo peligrar su alto nivel económico? Y nuestro Gutierre ¿sesgará la vida de Leonor ante la mínima sospecha de adulterio? En ambas obras, el homicidio ha sido gratuito, no ha habido pena judicial. En pleno siglo xxI, el desenlace de El médico de su honra nos parece más contemporáneo que el suicidio de Otelo; Calderón propone dos ideas básicas: una, la condena en vida: Gutierre debe convivir con sus propios fantasmas; otra, el libre arbitrio: ¿aplicará de nuevo don Gutierre la misma «medicina» a su nueva esposa? El final, muy de nuestro tiempo, queda abierto. El protagonista será libre para decidir igual que lo es el espectador, obnubilado en esa mezcla de consternación, desaliento y angustia, al caer el telón.

${ }^{28}$ Platón, Diálogos, II, p. 77.

${ }^{29}$ La polémica suscitada por la obra a lo largo de los siglos en toda Europa puede leerse en Armendáriz, en Calderón de la Barca, El médico de su honra, 2007, pp. 29-72.

${ }^{30}$ Antonio Regalado explica esta idea y la pone en relación, muy acertadamente, con uno de los grandes dramaturgos del siglo xx: Samuel Beckett. El filósofo nos muestra cómo don Gutierre queda "condenado a vivir el castigo de la existencia. Este pensamiento de Calderón, la existencia como castigo, no nos debería ser extraño, ya que ha servido a un gran dramaturgo de nuestra época como fundamento de su arte dramático. En nuestra centuria ha sido Samuel Beckett el dramaturgo que ha resucitado con más arte la idea de la existencia como castigo, pensamiento que inspira sus dramas y novelas»; en Regalado, 1995, I, p. 358.

${ }^{31}$ Match Point, dir. Woody Allen, BBC Films / DreamWorks Pictures, 2005. 


\section{c) Juez, defensa y fiscal: el pluriempleo del marido infamado}

Aunque ninguno de los caballeros supuestamente ofendidos sean hombres de leyes, lo cierto es que en las obras calderonianas actúan casi como tales; y esto, por un motivo evidente: porque los asuntos que concernían al matrimonio pertenecían al Derecho doméstico y la aplicación de la ley uxoricida era una cuestión de venganza privada; el marido, por tanto, tenía el poder para decidir qué hacer con los adúlteros. El esposo injuriado se convierte al mismo tiempo en juez y verdugo, abogado defensor y fiscal, y para ello, emite un veredicto basado en la mera sospecha.Y la sentencia en este caso, como explicaba el Aquinate, es siempre injusta, además de constituir un pecado mortal. Calderón no solo debía conocer esta teoría, sino que además se sirve del paradigma jurídico para exponer dichos razonamientos. Observemos el soliloquio que mantiene don Gutierre, en el que se alternan fiscal y defensa cual si de un juicio se tratase. Primero se exponen los hechos básicos: «Anoche llegué a mi casa, / es verdad; pero las puertas / me abrieron luego, y mi esposa / estaba segura y quieta». Como si el fiscal le increpase sobre la causa por la cual le avisaran de que había un hombre en la casa, él mismo haciendo de abogado defensor responde: «[...] tengo disculpa en que fue / la que me avisó ella misma». Sigue la acusación inquiriendo por qué se apagó la luz, de dónde pudo salir la daga o por qué la espada del infante estaba en su casa.Y don Gutierre se responde a sí mismo, encontrando soluciones que libren de sospecha a su esposa. Continúa el monólogo en su intento de defender a Mencía, recurriendo a la posibilidad de que una criada la hubiese traicionado y hubiese permitido la entrada al infante.Y si el oyente, como si fuese un tribunal contemporáneo, ya está medio convencido de la inocencia de Mencía, don Gutierre sigue en su empeño absolutorio, añadiendo como prueba fehaciente la hermosura de la misma, en un razonamiento que nos trae ecos platónicos, cuando belleza y bondad caminaban de la mano. Sin embargo, la defensa se trueca en acusación cuando don Gutierre recuerda que es un noble («soy quien soy») y aparece el honor, más que como un código ético, como una ley justiciera que aprisiona al individuo: «QQué injusta ley condena / que muera el inocente, que padezca?».

El mismo discernimiento nos lo encontramos en otros maridos aparentemente burlados, como don Lope de Almeida, don Curcio o don Vicente, quienes, ante el mero indicio de infidelidad de la esposa, deciden su condena sin esperar la prueba exigida por las leyes de la época. 
De esta forma, Calderón añadía fuerza dramática por un lado, y por otro concedía viva voz a la conciencia del individuo. Separa, así, el fuero externo, representado tanto por la ley y el código ético en todo su rigor, del fuero interno, en el que se gesta la propia individualidad del ser, su conciencia. Paolo Prodi, en Una historia de la justicia, señala al jesuita Paul Laymann como el primero en «separar de la esfera jurídico-positiva - en forma sistemática - el fuero interno, atribuido solo al nuevo Derecho de la conciencia». Así, este jesuita definió la conciencia como «el acto de la razón práctica acerca de las acciones particulares, deducido de los principios universales por razonamiento; dicho acto nos hace comprender qué es honesto y qué deshonesto» ${ }^{32}$. Los protagonistas calderonianos no se plantean la honestidad, sino la justicia. «¿Qué ley culpa a un inocente?», implora Curcio; o «Puede haber culpa sin castigo?», se pregunta don Juan Roca. Para Juana Sánchez-Gey, una de las propuestas nuevas que nos aporta el pensamiento de Calderón es precisamente éste, el de la conciencia ${ }^{33}$.

Otro hecho que hay que tener en cuenta es que los uxoricidas estaban aterrorizados por la opinión ajena («¿Qué opinión a un libre agravia?»). No es de extrañar el miedo social, cuando ellos mismos juzgan y condenan según su propia opinión.Y es que el honor iba estrechamente vinculado a la reputación y ésta, a la sociedad. El orden social jugaba un papel prioritario, y el adulterio era uno de los atentados principales contra la moral y las buenas costumbres ${ }^{34}$. Josefa Castilla Soto nos recuerda la concepción del honor imperante desde la Edad Media, así como la diferente concepción entre el hombre y la mujer:

Ya desde el siglo xiIr el honor aparece definido en el código castellano de las Partidas como «la reputación que el hombre ha adquirido por el rango que ocupa, por las hazañas o por el valor que en él se manifiesta». El honor debía regir el comportamiento de un caballero respecto a los deberes de obediencia o lealtad ante Dios, ante el rey, ante el amigo y ante la mujer.

32 Prodi, 2008, p. 334.

33 Sánchez-Gey Venegas, 2001, p. 170.

${ }^{34}$ La investigadora jurídica María Viviana Caruso nos cuenta cómo el uxoricidio no fue derogado hasta 1963, siendo considerado «el más grave de todos los delitos contra la honestidad, pues es el que más grande perturbación causa a la familia y, por ende, a la sociedad»; en Caruso Fontán, 2006, p. 30. 
En el caso del hombre, el honor se define por medio de la reputación que debe defender con su vida. En el caso de la mujer casada, el honor reside en la fidelidad, mientras que en el de la joven lo hace en su virginidad.

El honor lleva a la honra o reconocimiento del honor en un individuo por los demás. Es decir, no bastaba con ser virtuoso y tener méritos, además era necesario que fueran reconocidos por los demás ${ }^{35}$.

El uso social y la ley, consintiendo el uxoricidio, causaban un doble juego en el que el marido burlado, primer perjudicado, se convertía en verdugo y víctima al mismo tiempo, y la esposa adúltera pasaba de sujeto activo a sujeto pasivo y víctima principal. El lamento de don Lope, don Curcio o don Juan Roca ante la injusta ley que les culpa sin haber cometido el delito ataca la esencia misma de la justicia: no se puede condenar al inocente. Por eso Alexander A. Parker nos habla de conmiseración hacia los protagonistas de los dramas de honor; encuentra en estas obras, y concretamente en El médico de su honra, «un sentido trágico de la vida» ${ }^{36}$.

La importancia jurídica de los soliloquios de los protagonistas no solo se expresa a través del conflicto justicia conmutativa versus conciencia, sino que hay todo un lenguaje técnico propio de letrado en ejercicio. Sirviéndose del paradigma jurídico, Calderón convierte en víctima al mismo verdugo. Logra, además, la conmiseración del público al exhibir a un hombre atrapado entre la ley, el deber del noble y una justicia conmutativa que permitía la venganza y la muerte de los adúlteros como contrapartida.

\section{d) Justicia conmutativa en dramas, comedias y autos}

Calderón expone el delito de uxoricidio, la justicia conmutativa y sus consecuencias en los dramas mencionados anteriormente, pero también podemos encontrarlo en sus comedias y autos. En las primeras no es un tema relevante, aunque la justicia conmutativa sea la propia de las comedias de capa y espada; en la mayoría de los casos, la acción se centra en damas y caballeros solteros y la obra finaliza con el matrimo-

35 Castilla Soto, 2004, p. 370.

${ }^{36}$ Parker, 1991, pp. 286-287. 
nio $^{37}$. La problemática del honor se produce normalmente entre padres y hermanos, pero no entre maridos. También esta cuestión forma parte de la justicia conmutativa, porque incluye la venganza privada, pero no es uxoricidio. Un ejemplo de comedia en el que se trata este delito aparece, como se ha mencionado anteriormente, en Gustos y disgustos no son más que imaginación.

La primera diferencia que observamos respecto a las tragedias vistas anteriormente es que, en la comedia, el uxoricidio no llega a producirse. El final, como corresponde al género, es feliz. Doña Violante vive, pese a sus miedos y tribulaciones («Honor, ¿qué he de hacer? Si intento / volver a mi cuarto hoy, / dispuesta a mi muerte voy; / si temerosa me ausento, / añado otro fundamento. / Ir es desesperación; / no ir, confirmar traición») $)^{38}$. Por otro lado, las intenciones de don Vicente son claras y no cesará en su empeño hasta que no descubra la inocencia de la esposa ${ }^{39}$. Su sentido de la justicia se hace evidente a través de sus palabras. No atenta contra el rey, ya hemos visto el motivo, y sí va a hacerlo contra su esposa. Si la justicia conmutativa requería una proporción entre el delito cometido y la retribución, las palabras del protagonista lo dejan claro. Si el deshonor mata socialmente al marido burlado («voy cadáver con alma»), lo justo para don Vicente es aplicar la muerte de la esposa. El carácter privativo de este tipo de venganza no solo se basaba en la justicia conmutativa, sino que además era el exponente de la concepción que se tenía del matrimonio en la época: Derecho doméstico. Así lo refiere santo Tomás en la Suma ${ }^{40}$, y así lo afirma Domingo Báñez cuando explica las consecuencias de esta concepción jurídica en la que el varón tiene potestad absoluta respecto a su mujer en todo lo referente al régimen doméstico ${ }^{41}$.

Si hasta ahora hemos visto aplicar la ley en todo su rigor y convertir la justicia vengativa en injusticia, otorgando la misma respuesta al conflicto pero con diferente resultado en los dramas y la comedia expuestos, también la solución que otorga Calderón en el auto sacramental El pintor de su deshonra difiere de las anteriores. En vez de una justicia conmu-

\footnotetext{
${ }^{37}$ La diferencia entre las comedias que finalizan con el matrimonio y los dramas que comienzan precisamente con la boda es analizada por la profesora doña María del Carmen Bobes Naves en un artículo titulado «Comedias de honor y celos» (2004).

${ }^{38}$ Calderón de la Barca, Gustos y disgustos no son más que imaginación, p. 989b.

39 Calderón de la Barca, Gustos y disgustos no son más que imaginación, p. 989a.

40 Tomás de Aquino, Suma teológica, II-II, c. 57, art. 4.

${ }^{41}$ Báñez, 2008, p. 87.
} 
tativa en la que prima la venganza, Calderón se acerca más a una justicia divina, prevaleciendo la misericordia. En el auto, el dramaturgo mantiene una postura afin a la de la Iglesia católica, que pregonaba el perdón frente a la venganza ${ }^{42}$. El Pintor (Dios) perdona a su esposa (Naturaleza) y castiga a Lucero, su amante. A pesar de las semejanzas con el drama, la solución que se plantea es bien distinta. Mientras que en el drama don Juan de Roca ejerce su derecho sobre la muerte del amante y su mujer, quedando absuelto de su delito por el Príncipe, en el auto el Pintor perdona a su esposa y muere Lucero al no mostrar arrepentimiento. La sorpresa final es tan grande que Calderón juega con el uxoricidio convirtiendo la costumbre de la venganza en perdón divino e invirtiendo el orden de valores. La moral cristiana, con su defensa a ultranza de la vida, se contraponía de lleno al código del honor ${ }^{43}$. La diferencia entre la venganza y el perdón en estos dos códigos puede observarse claramente en el pasaje de El pintor de su deshonra (auto) en el que Culpa y Lucero, e incluso la propia Naturaleza, proponen a Pintor el vengar la infidelidad, como lo exigía el código del honor, frente a la propuesta cristiana de Pintor $^{44}$.Alan K. G. Paterson, en la edición crítica del auto, explica cómo en éste se «invierte el modelo»: «Esta inversión representa la subversión del modelo profano [...]. Como el duelo acaba en matar a quien no llora (Lucero, el raptor) y en no matar a quien llora (Naturaleza humana, la mujer raptada), no corresponde a la costumbre ${ }^{45}$.

Otra diferencia evidente es que en las tragedias de honor los personajes se quejan de la ley del duelo, mientras que ni en el auto, ni en

\footnotetext{
42 «Los moralistas, aunque sancionaban el código del honor en lo relativo al doble patrón para juzgar el adulterio femenino y el masculino, lo rechazaban en lo referente a la ejecución de la venganza. En este punto, la posición de la Iglesia fue muy tajante; los moralistas solían condenar sin paliativos esta práctica. Para ello se apoyaban en el pasaje de la mujer adúltera del Evangelio:"No dio Cristo licencia de apedrear a la mujer adúltera”, escribe Osuna. [...] Juan de la Cerda [...] afirma: "Uno de los grandes errores que hay en el mundo es que quiera el hombre con acuerdo de su voluntad hacer un tan gran mal como quitar la vida a una mujer que en tanto tiempo quiso y amó, por solo cumplir con los hombres malos y mundanos y satisfacer al vulgo. Cuánto mejor es que mire el casado a Dios".Y añade: "De cuán nobleza y cristiandad usa el hombre que deja de matar a su mujer, hallándola en adulterio"”; en Vigil, 1986, p. 148.

${ }^{43}$ Erik Coenen, muy acertadamente, habla de una "coexistencia de ambos códigos», cuya expresión máxima podemos observarla en el tratamiento del uxoricidio de los dramas y auto mencionado. Calderón de la Barca, $A$ secreto agravio, secreta venganza, p. 45.

${ }^{44}$ Calderón de la Barca, El pintor de su deshonra, p. 191.

45 Calderón de la Barca, El pintor de su deshonra, p. 191.
} 
la comedia aparece lamento alguno. Prima en ambos la acción sobre el sentimiento, no dejando traslucir su conciencia. La diferencia esencial que distingue dramas, comedias y autos radica en el final trágico de los primeros, en el final feliz del segundo, mientras que en el tercero se invierte el orden de valores, implantándose una nueva justicia: la clemencia y el perdón en quien se arrepiente. La justicia conmutativa amparada en la venganza privada y en las leyes vigentes caracteriza dramas y comedias. La solución jurídica es la misma en ambos, solo que en la comedia el enredo se deshace y el final es feliz. Los resultados son, por tanto, fieles al género dramático ante el que nos enfrentemos. No hay que olvidar que Calderón tenía, en efecto, estudios jurídicos y conocía las leyes y el pensamiento filosófico de su época; pero, ante todo, era un dramaturgo. Si investigadores como Claude Chauchadis o Arellano resaltan la diferencia del tratamiento del honor en un drama o en una comedia de capa y espada ${ }^{46}$, y Armendáriz Aramendía señala esta diferencia de género no solo en el teatro sino en toda la literatura del Siglo de $\mathrm{Oro}^{47}$, nos atrevemos a sugerir que Calderón diferencia no solo el tema del honor, sino que, en este delito, dramas y comedias son el prototipo de la justicia humana conmutativa, mientras que el auto lo es de la justicia divina.

\footnotetext{
46 Chauchadis, 1987, pp. 106-107, cit. Antonucci en Calderón de la Barca, La dama duende, p. LI, y Arellano, 1988, p. 46: «Dentro del universo de la comedia de capa y espada, el honor, como otros elementos, es un componente explotado en sus potencialidades cómicas».

${ }^{47}$ Armendáriz, en Calderón de la Barca, El médico de su honra, 2007, p. 28.
} 


\section{BiBLIOGRAFÍA}

Arellano, Ignacio, «Convenciones y rasgos genéricos en la comedia de capa y espada», Cuadernos de Teatro Clásico, 1, 1988, pp. 27-49.

Arellano, Ignacio, «Grandes temas de los dramas de Calderón y su pervivencia», en Calderón, innovación y legado: Actas selectas del IX Congreso de la Asociación Internacional de Teatro Español y Novohispano de los Siglos de Oro, en colaboración con el Grupo de Investigación Siglo de Oro de la Universidad de Navarra, Pamplona, 27 al 29 de marzo de 2000, dir. Ignacio Arellano, Germán Vega García-Luengos, New York, Peter Lang, 2000, pp. 3-16.

Aristóteles, Ética a Nicómaco, introd., trad. y notas José Luis Calvo Martínez, Madrid, Alianza, 2004 [2001].

Báñez, Domingo (O. P.), El Derecho y la justicia, introd., trad. y notas Juan Cruz Cruz, Pamplona, Eunsa, 2008.

Bobes NAves, María del Carmen, «Comedias de honor y celos», en Largo mundo alumiado: estudios em homenagem a Vitor Aguiar e Silva, ed. Carlos Mendes de Sousa, Rita Patricio, Braga, Universidad de Minho / Centro de Estudios Humanísticos, 2004, vol. II, pp. 745-759.

CaAmaño Rojo, María J., El mayor monstruo del mundo: estudio textual, Santiago de Compostela, Universidad de Santiago de Compostela, 2001.

CaAmaño Rojo, María J., «El texto de El mayor monstruo del mundo», en Calderón 2000: homenaje a Kurt Reichenberger en su 80 cumpleaños: Actas del Congreso Internacional IV Centenario del Nacimiento de Calderón, Universidad de Navarra, septiembre 2000, dir. Ignacio Arellano, Kassel, Reichenberger, 2002, vol. II, pp. 73-83.

Calderón de la Barca, Pedro, A secreto agravio, secreta venganza, ed. Erik Coenen, Madrid, Cátedra, 2011.

Calderón de la Barca, Pedro, Dramas de honor, I, ed. Ángel Valbuena Briones, Madrid, Espasa Calpe, 1967, vol. II.

Calderón de la Barca, Pedro, El mayor monstruo del mundo, en Obras Completas. I: Dramas, ed. Luis Astrana Marín, Madrid, Aguilar, 1951, pp. 257-293.

Calderón de la Barca, Pedro, El médico de su honra, ed. Don William Cruickshank, Madrid, Castalia, 1989.

Calderón de la Barca, Pedro, El médico de su honra, ed. Ana Armendáriz, Madrid / Frankfurt, Iberoamericana / Vervuert, 2007.

Calderón de la Barca, Pedro, El médico de su honra, ed. Jesús Pérez Magallón, Madrid, Cátedra, 2012.

Calderón de la Barca, Pedro, El pintor de su deshonra, ed. Alan K. G. Paterson, Pamplona / Kassel, Universidad de Navarra / Reichenberger, 2011.

Calderón de la Barca, Pedro, Gustos y disgustos no son más que imaginación, en Obras Completas. II: Comedias, ed. Ángel Valbuena Briones, Madrid, Aguilar, 1956, pp. 953-993. 
Calderón de la Barca, Pedro, La dama duende, ed. Fausta Antonucci, est. prelim. M.Vitse, Barcelona, Círculo de Lectores / Galaxia Gutenberg, 2006.

Calderón de la Barca, Pedro, La devoción de la Cruz, ed. Sidney F. Wexler, Salamanca, Anaya, 1966.

Calderón de la Barca, Pedro, La devoción de la Cruz, ed. Manuel Delgado, Madrid, Cátedra, 2000.

Calderón de la Barca, Pedro, Obras Completas. I: Dramas, ed. Luis Astrana Marín, Madrid, Aguilar, 1951.

Calderón de la Barca, Pedro, Obras Completas. II: Comedias, ed. ÁngelValbuena Briones, Madrid, Aguilar, 1956.

Calderón de la Barca, Pedro, Obras Completas. III: Autos sacramentales, ed. Ángel Valbuena Prat, Madrid, Aguilar, 1952.

Calderón de la Barca, Pedro, Primera parte de comedias, ed. Luis Iglesias Feijoo, Madrid, Biblioteca Castro, 2006.

Carranza, Bartolomé, Tratado sobre la virtud de la justicia [1540], transcr., trad. y verificación de fuentes Teodoro López, Ignacio Jericó Bermejo, Rodrigo Muñoz de Juana, Pamplona, Eunsa, 2003.

Caruso Fontán, María Viviana, Nuevas perspectivas sobre los delitos contra la libertad sexual, Valencia, Tirant lo Blanch, 2006.

Castilla Soto, Josefina, "La sociedad española del Barroco», en Actas del IV Centenario del Nacimiento de Don Pedro Calderón de la Barca, ed. Manuel Abad Varela, Madrid, Universidad Nacional de Educación a Distancia, 2004, pp. 361-370.

Chauchadis, Claude, «Libro y leyes del duelo en el Siglo de Oro», Criticón, Toulouse, Universidad de Toulouse-Le Mirail, 39, 1987, pp. 77-113.

Chauchadis, Claude, «El duelo como valor aristocrático en la comedia», en Actas del IV Congreso Internacional de la Asociación Internacional Siglo de Oro (AISO) (Alcalá de Henares, 2227 de julio de 1996), ed. María Cruz García de Enterría, Alicia Cordón Mesa, Alcalá de Henares, Universidad de Alcalá, Servicio de Publicaciones, 1998, pp. 485-494.

Códigos españoles, concordados y anotados, Los, Madrid, Antonio de San Martín, 1872.

Connejo, Andrés, Diccionario histórico y forense del Derecho real de España, Madrid, Joaquín Ibarra, 1779. Disponible en: <http://books.google.es/books?id=4 xIzW7r64lcC\&printsec $=$ frontcover\&hl $=$ es\&source $=$ gbs_ge_summary_r\&c $\mathrm{ad}=0 \# \mathrm{v}=$ onepage $\& \mathrm{q} \& \mathrm{f}=$ false $>$ [fecha de acceso: $28 / 01 / 2014]$.

Corominas, Joan, Diccionario crítico etimológico castellano e hispánico, Madrid, Gredos, 1974.

Diana, Antonino, Suma: recopilado en romance, Madrid, Melchor Sánchez, 1657. Disponible en: <https://play.google.com/books/reader?id=6cNOPq1KJHQ C\&printsec $=$ frontcover\&output $=$ reader\&hl $=$ es\&pg $=$ GBS.PP5 $>[$ fecha de acceso: 03/10/2013]. 
Diccionario de la Real Academia Española (DRAE), 2001, 22. ${ }^{a}$ ed. Disponible en Internet: <http://buscon.rae.es/drae/> [fecha de acceso: 31/07/2015].

Entwistle, William J., «Honor in Spanish Golden-Age Drama: It's Relation to Real Life and to Morals», Bulletin of Hispanic Studies, 35, 4, 1958, pp. 199-210.

García Hernán, David, La nobleza en la España moderna, Madrid, Istmo, 1992.

GÉrARD, André S., "The Loving Killers: The Rationale of Righteousness in Baroque Tragedy», Comparative Literature Studies, 2, 3, 1965, pp. 209-232.

GESÙ, Floriana Di, «Función dramática de la escena interior y de la exterior en El médico de su honra», en Calderón 2000: homenaje a Kurt Reichenberger en su 80 cumpleaños: Actas del Congreso Internacional IV Centenario del Nacimiento de Calderón, Universidad de Navarra, septiembre 2000, dir. Ignacio Arellano, Kassel, Reichenberger, 2002, vol. II, pp. 143-150.

Lorenzo Vián, Remedios, "Calderón y su época: algunos aspectos jurídicos del matrimonio y la familia», en Calderón, una lectura desde el siglo XXI, coord. María Gómez y Patiño, Alicante, Instituto Alicantino de Cultura Juan GilAlbert, 2000, pp. 163-176.

Menéndez Pidal, Ramón, «Del honor en el teatro español», en De Cervantes $y$ Lope de Vega, Madrid, Espasa Calpe, 1945, pp. 145-173.

Novísima recopilación de las leyes de España [1805], ed. facs., Madrid, Imprenta Nacional del Boletín Oficial del Estado, 1992.

PARKer, Alexander A., La imaginación y el arte de Calderón: ensayos sobre las comedias, Madrid, Cátedra, 1991.

Pérez Martín, Antonio y Johannes-Michael Scholz, Legislación y jurisprudencia en la España del Antiguo Régimen,Valencia, Universidad de Valencia, 1978.

Platón, Diálogos, II, Madrid, Gredos, 2007.

Platón, Gorgias, en Obras Completas, Madrid, Aguilar, 1993.

Prodi, Paolo, Una historia de la justicia, trad. Luciano Padilla López, Buenos Aires, Katz, 2008.

Regalado, Antonio, Los orígenes de la modernidad en la España del Siglo de Oro, Barcelona, Destino, 1995, 2 vols.

Rodríguez Paniagua, José María, Historia del pensamiento jurídico: de Heráclito a la Revolución francesa, Madrid, Universidad Complutense de Madrid, 1996, vol. I.

SÁnchez-Gey Venegas, Juana, «Sobre el hombre calderoniano o la razón de una duda», en Calderón de la Barca desde la modernidad, ed. Felipe Pedraza Jiménez y otros, Madrid, Fundación Fernando Rielo, 2001, pp. 161-172.

Soto, Fray Domingo de, La justicia y el Derecho, trad. Jaime Torrubiano Ripoll, Madrid, Reus, 1922, vol. I.

Soto, Fray Domingo de, Tratado de la justicia y el Derecho, trad.Jaime Torrubiano Ripoll, Madrid, Reus, 1926, vol. II. 
SuÁrez, Francisco, Guerra, intervención, paz internacional, trad. Luciano Pereña Vicente, Madrid, Espasa Calpe, 1956.

SuÁrez, Francisco, De legibus, liber $V$, De varietat legum humanarum et praesertim de odiosis, ed. bil. Carlos Baciero, Ana María Barrero, Jesús María Garrcía Añoveros, José María M. Soto, Madrid, Centro Superior de Investigaciones Científicas, 2010.

Sullivan, Henry W., "The Problematic of Tragedy in Calderón's El médico de su honra», Revista Canadiense de Estudios Hispánicos, 5, 3, 1981, pp. 355-377.

Testamento e inventario de bienes de P. Calderón en el Archivo Histórico de Protocolos de Madrid, ed. Carlos Baztán Lacasa, Madrid, Consejería de Cultura, 2000.

Tirso de Molina, La celosa de sí misma, ed. Gregorio Torres Nebrera, Madrid, Cátedra, 2005.

Tomás de Aquino, Suma teológica, Madrid, BAC, 1993-2003, 5 vols.

Tomás y Valiente, Francisco, Manual de Historia del Derecho español, Madrid, Tecnos, 2004 [1979].

Vacant, Alfred, Mangenot, Eugène y Amann, Emile, Dictionnaire de Théologie Catholique, XIII, Paris, Libraire Letouzey et Ané, 1936.

Valdés Pozueco, Catarina, «Dña. Ángela y Dña. Mencía: dos respuestas ante la ley», en Compostella Aurea:Actas del VIII Congreso de la Asociación Internacional del Siglo de Oro (AISO), Santiago de Compostela, 711 de julio de 2008, ed.Antonio Azaustre Galiana y Santiago Fernández Mosquera, Santiago de Compostela, Universidad de Santiago de Compostela, 2008, vol. III, pp. 7-11.

Valdés Pozueco, Catarina, El mundo jurídico de Calderón y su sentido de la justicia humana, tesis doctoral inédita, Madrid, Universidad Nacional de Educación a Distancia, 2015.

VEGA, Lope de, Arte nuevo de hacer comedias en este tiempo [1609], ed. Juan Manuel Rozas, Alicante, Biblioteca Virtual Miguel de Cervantes, 2002 [1976]. Disponible en: <http://www.cervantesvirtual.com/nd/ark:/59851/bmcms3r3> [fecha de acceso: 04/09/2013].

Vega, Lope de, La locura por la honra [1618], Alicante, Biblioteca Virtual Miguel de Cervantes, 2009. Disponible en: <www.cervantesvirtual.com/nd/ ark:/59851/bmcq5345> [fecha de acceso: 04/09/2013].

VIGIL, Mariló, La vida de las mujeres en los siglos XVI y XVII, Madrid, Siglo XXI, 1986. 